\author{
Artykuł oryginalny/Articles
}

\title{
Opracowanie dynamicznych testów kontroli jakości kolimatora wielolistkowego przy użyciu oprogramowania Artiscan.
}

\section{Development of quality control dynamic tests of Multileaf Collimator with Artiscan software.}

\author{
Hubert Szweda ${ }^{1}$, Piotr Romański ${ }^{2}$, \\ Krzysztof Matuszewski ${ }^{1}$, Bartosz Pawałowski ${ }^{1}$ \\ ${ }^{1}$ Pracownia Dozymetrii Aparatury Medycznej, Wielkopolskie Centrum Onkologii, Poznań, Polska \\ ${ }^{2}$ Pracownia Dozymetrii Klinicznej, Wielkopolskie Centrum Onkologii, Poznań, Polska
}

\section{Streszczenie}

Odpowiednia kontrola jakości kolimatora wielolistkowego jest bardzo istotnym elementem każdego programu zapewnienia jakości radioterapii. Wyróżnia się dwie metody kontroli jakości kolimatora wielolistkowego (ang. multileaf collimator - MLC). Pierwsza z nich to patient specific quality assurance (ang. quality assurance - QA) zakładająca, że każdy plan terapeutyczny musi zostać zweryfikowany i sprawdzony przed rozpoczęciem leczenia przez pacjenta. Druga metoda to machine specific QA, która zakłada, że parametry pracy MLC powinny być sprawdzane i kontrolowane w systematycznych odstępach czasu. Głównym celem pracy było wykonanie dedykowanych testów i opracowanie protokołów kontroli jakości pracy MLC. Protokoły zostały opracowane przy użyciu oprogramowania Artiscan firmy Aquilab, które służy do automatycznej analizy i oceny obrazów. Testy MLC przeprowadzone zostały na trzech akceleratorach liniowych firmy Varian, modele: TrueBeam, Clinac 2300CD-S oraz Unique. Do zebrania obrazów DICOM użyto elektronicznych detektorów obrazowych, zainstalowanych w akceleratorach. Bazując na otrzymanych wynikach, wyznaczono wartości referencyjne dla wszystkich testów dynamicznych. Dla testów dMLC dosimetry, Dose Rate/Gantry Speed oraz MLC Speed wyznaczono 2\% tolerancje. Dla testów Static Picket Fence oraz Rapid Picket Fence ustalono 0,70mm tolerancje. Opracowane protokoły QA w sposób znaczący przyczyniły się do optymalizacji całego procesu kontroli jakości, czyniąc go szybszym, wydajniejszym i bardziej zautomatyzowanym, pozwalając na analizę dużej ilości obrazów DICOM w krótkim czasie.

Adres do korespondencji

Hubert Szweda

Pracownia Dozymetrii Aparatury Medycznej

Wielkopolskie Centrum Onkologii, ul. Garbary 15, 61-866 Poznań, Polska

Telefon. +48 623322549

e-mail: hubert.szweda@wco.pl 


\begin{abstract}
Appropriate quality control of MLC is one of the main part of every quality assurance program. There are two methods of MLC quality control. First method is the patient specific QA, assumes that every treatment plan has to be verified before starting the treatment. Second method is machine specific QA, assumes that MLC parameters should be check every settled period of time. The main purpose of this work was to perform appropriate tests and to develop protocols used in machine specific quality control of MLC. QA protocols were developed with Artiscan software, used for automatic image analysis. QA tests have been performed on three Varian linear accelerators: TrueBeam, Clinac $2300 \mathrm{CD}-\mathrm{S}$ and Unique. Electronic portal imaging devices installed on linacs were used to collect DICOM images. Based on the obtained results, the reference values of MLC parameters were determined. For dMLC, dose rate/gantry speed and MLC tests appointed 2\% tolerance. For the Static and Rapid Picket Fence $0,70 \mathrm{~mm}$ tolerance was suggested. Developed protocols significantly optimized the quality assurance process, making it faster, more automated and efficient.
\end{abstract}

Stowa kluczowe: MLC, kolimator wielolistkowy, kontrola jakości, Artiscan

Key words: MLC, multileaf collimator, quality assurance, machine specific QA, Artiscan.

\title{
Wstęp
}

Dynamiczne techniki radioterapii stosowane są w praktyce klinicznej od ostatniej dekady XX wieku. [1]. Metody te wymagają bardzo precyzyjnego dopasowania rozkładu dawki do obszaru napromienianej zmiany, co jest możliwe do osiągnięcia dzięki użyciu kolimatora wielolistkowego, który jest integralną częścią medycznych akceleratorów liniowych. Zadaniem kolimatora wielolistkowego jest precyzyjne ukształtowanie rozkładu dawki w napromienianej objętości, przy jednoczesnej jej minimalizacji w zdrowych tkankach i narządach [2]. Każdy z listków wyposażony jest w samodzielny silniczek, dzięki któremu listki mogą poruszać się niezależnie względem siebie. Listki kolimatora akceleratorów firmy Varian Medical Systems poruszają się z dokładnością $1 \mathrm{~mm}$ dla technik z modulowaną intensywnością wiązki (ang. intensitymodulated radiotherapy - IMRT) oraz 2,5mm dla wielołukowych technik dynamicznych (ang. volumetric modulated arc therapy -VMAT) [3]. Prawidłowe działanie i praca listków są więc niezbędne do precyzyjnego dostarczenia dawki promieniowania do obszaru zaplanowanego (ang. planning target volume - PTV). Celem kontroli pracy MLC konieczne jest opracowanie odpowiednich procedur i testów kontroli jakości. Właściwy program kontroli jakości zapewnia, że cały proces radioterapii realizowany będzie w sposób bezpieczny i optymalny dla pacjenta. Dodatkowo pozwala wyeliminować błędy, wynikające z nieprawidłowej pracy aparatu terapeutycznego. [4-5].

\section{Cel pracy}

Głównym celem pracy było opracowanie wzorcowych protokołów kontroli jakości kolimatora wielolistkowego przy użyciu oprogramowania do automatycznej analizy obrazów Artiscan, firmy Aquilab. Celem szczegółowym było wyznaczenie wartości referencyjnych dla wszystkich parametrów MLC otrzymywanych podczas wykonywania testów dynamicznych, a także zaimplementowanie odpowiednich poziomów tolerancji.

\section{Material}

Wszystkie pomiary wykonano na akceleratorach medycznych zainstalowanych w Wielkopolskim Centrum Onkologii w Poznaniu. Wybrano trzy modele firmy Varian Medical Systems: TrueBeam, Clinac 2300 CD-S oraz UNIQUE. Aparaty te zdolne są do realizacji takich procedur jak: radioterapia z modulowaną intensywnością wiązki oraz lukowa technika dynamiczna. Każdy z akceleratorów wyposażony jest w kolimator wielolistkowy posiadający 120 listków (40 par listków o grubości $5 \mathrm{~mm}$ i 20 par listków o grubości $10 \mathrm{~mm}$ ). Elektroniczne detektory obrazowe (ang. electronic portal imaging devices - EPID), zainstalowane 
w aparatach terapeutycznych to Varian Portal Vision aS10oo, o rozdzielczości 1024×768, przy maksymalnych wymiarach $40 \times 30 \mathrm{~cm}$. [6-8]. Do przeprowadzenia pomiarów nie użyto dodatkowych fantomów.

\section{Metoda}

Pierwszym etapem pracy było zaimportowanie dedykowanych planów kontroli jakości do systemu planowania leczenia. Poszczególne pola różniły się takimi parametrami jak: wielkość pola, pozycja MLC, moc dawki, liczba jednostek monitorowych, prędkość obrotu głowicy i przesuwu listków. Do zebrania obrazów użyto elektronicznego detektora obrazowego. Odległość detektora od źródła promieniowania wynosiła $118,5 \mathrm{~cm}$. Do analizy otrzymanych obrazów użyto oprogramowana Artiscan. Oprogramowanie umożliwia analizę ilościową obrazów, co skutkuje uniezależnieniem się od subiektywnej oceny wyników danego testu. Łącznie przeprowadzono pięć niezależnych względem siebie testów [9].

Test dMLC Dosimetry - Celem testu jest sprawdzenie wpływu siły grawitacji na ruch listków oraz dostarczaną dawkę promieniowania. Niezbędne jest uzyskanie 4 obrazów (Ryc. 1), podczas których zmienia się pozycja ramienia $\left(0^{\circ}, 90^{\circ}, 180^{\circ}, 270^{\circ}\right)$. Wielkość pola, ilość jednostek monitorowych, rozkład oraz prędkość poruszania się listków dla każdego pola pozostaje niezmienna. Dawka ekwiwalentna wyrażona jest w jednostkach kalibracyjnych (ang. Calibrated Units - CU).

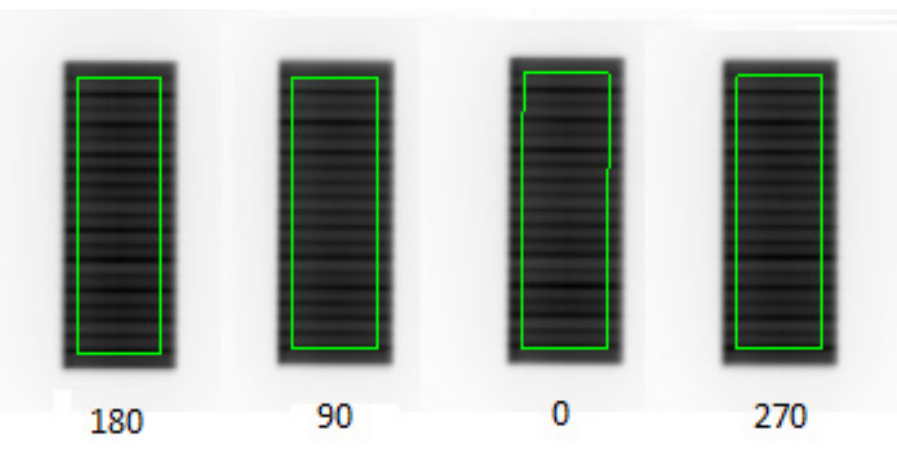

Ryc. 1. Zebrane obrazy dla testu dMLC dosimetry [Źródło: rycina własna].

Dla każdego pola obliczana jest różnica w dostarczonej dawce, wyrażona procentowo, zgodnie ze wzorem (1):

Gdzie:

$$
\mathrm{d}=\frac{\mathrm{D}_{\mathrm{m}}-\mathrm{D}_{\mathrm{i}}}{\mathrm{D}_{\mathrm{m}}} \times 100 \%
$$

$\mathrm{d}$ - znormalizowana różnica w dawce ekwiwalentnej [\%],

$\mathrm{D}_{\mathrm{m}}$ - średnia dawka ekwiwalentna [CU],

$\mathrm{D}_{\mathrm{i}}$ - dawka ekwiwalentna zmierzona dla pola i (gdzie i jest pozycją ramienia: $\mathrm{O}^{\circ}, 90^{\circ}, 180^{\circ}, 270^{\circ}$ ) [CU].

Test Static Picket Fence - Test pozwala na ocenę dokładności pozycjonowania listków kolimatora dla 4 różnych ustawień ramienia akceleratora medycznego, podczas realizacji pól dynamicznych, w trakcie których listki kolimatora wykonują ruch w trakcie napromieniania (Ryc. 2). Kontrola listków odbywa się za pomocą analizy trzech parametrów:

(a) Szerokość szczeliny - szerokość szczeliny pomiędzy listkami obliczana jest w każdym punkcie, w czasie gdy listki nie wykonują ruchu. Krawędzie szczelin wyznaczane są na podstawie procentowej wartości profilu. Obliczana jest zarówno szerokość szczeliny (mm) jak i dawka ekwiwalentna (CU) dla każdej pary listków.

(b) Odległość krawędzi listka od środka geometrycznego szczeliny - referencyjna pozycja centrum szczeliny dla każdej pary listków obliczana jest z regresji liniowej. Dla każdej pary listków kolimatora wyznaczana jest odległość pomiędzy środkiem szczeliny a pozycją referencyjną. Różnica między 
dwiema pozycjami wyrażona jest w mm.

(c) Dawka ekwiwalentna - Dawka ekwiwalentna obliczana jest dla każdej szczeliny listków, wyrażona w CU. Obliczana jest również średnia dawka ekwiwalentna oraz odchylenie standardowe. Dla kątów ramienia $90^{\circ}, 180^{\circ}$ i $270^{\circ}$ obliczany jest błąd bezwzględny pomiędzy średnią wartością błędów z danej pozycji w porównaniu do wyników uzyskanych dla kąta ramienia $\mathrm{O}^{\circ}$.

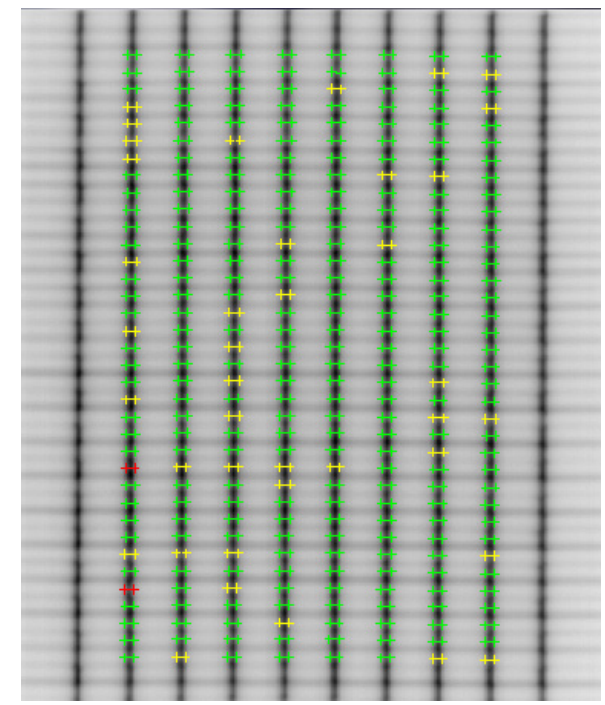

Ryc. 2. Otrzymany obraz dla testu Static Picket Fence [Źródło: rycina własna].

Test Rapid Picket Fence - Test polegający na sprawdzeniu pozycji i prędkości poruszania się listków, podczas jednoczesnego ruchu głowicy aparatu (technika RapidArc). Wszystkie parametry wyznaczane są w sposób analogiczny do testu Static Picket Fence.

Test Dose Rate/Gantry Speed - Test sprawdzający jednorodność dostarczonej dawki w zależności od szybkości ruchu głowicy i mocy dawki. Zebrany obraz składa się z 7 segmentów. W każdym regionie dawka promieniowania została dostarczona z inną prędkością obrotu głowicy i mocy dawki. Porównanie wszystkich siedmiu obszarów pozwala na kontrolę równomierności dostarczania dawki w zależności od prędkości głowicy oraz mocy dawki (Ryc. 3). Obliczona dawka z pola normalizowana jest do pola otwartego. W każdym z siedmiu segmentów obliczana jest dawka ekwiwalentna (CU) oraz odchylenie standardowe. Różnica między poszczególnymi segmentami wyrażona jest w procentach.

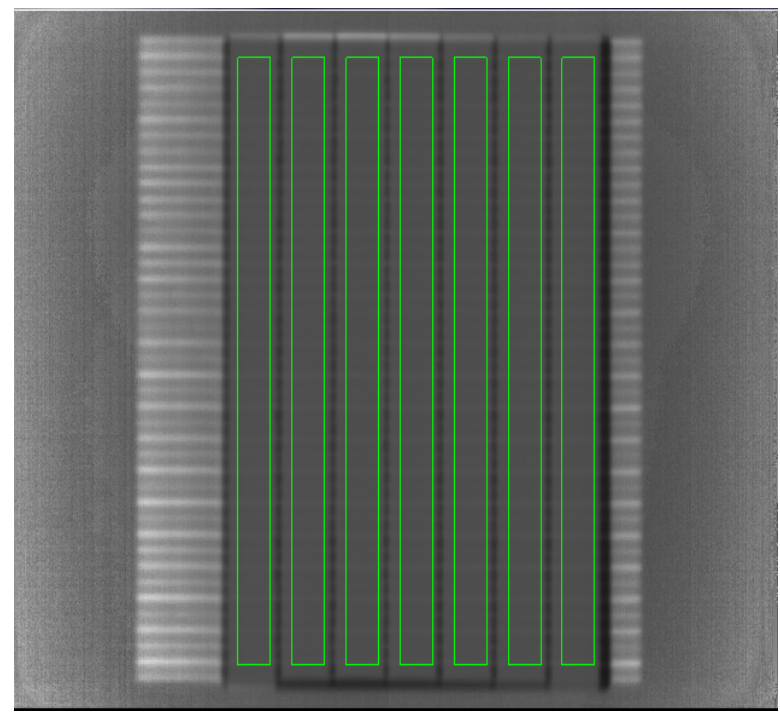

Ryc. 3. Otrzymany obraz dla testu Dose Rate/Gantry Speed [Źródło: rycina własna]. 
Test MLC Speed - Test pozwalający kontrolować jednorodność dostarczania dawki w zależności od różnej prędkości poruszania się listków. Pole podzielone jest na 4 segmenty, każdy segment napromieniany jest przy różnej prędkości przesuwu listków. Dawka w każdym obszarze powinna być tak sama (Ryc. 4). W każdym segmencie obliczana jest dawka ekwiwalentna (CU) i porównywana do pola otwartego. Różnice pomiędzy poszczególnymi regionami wyrażone są w procentach [14].

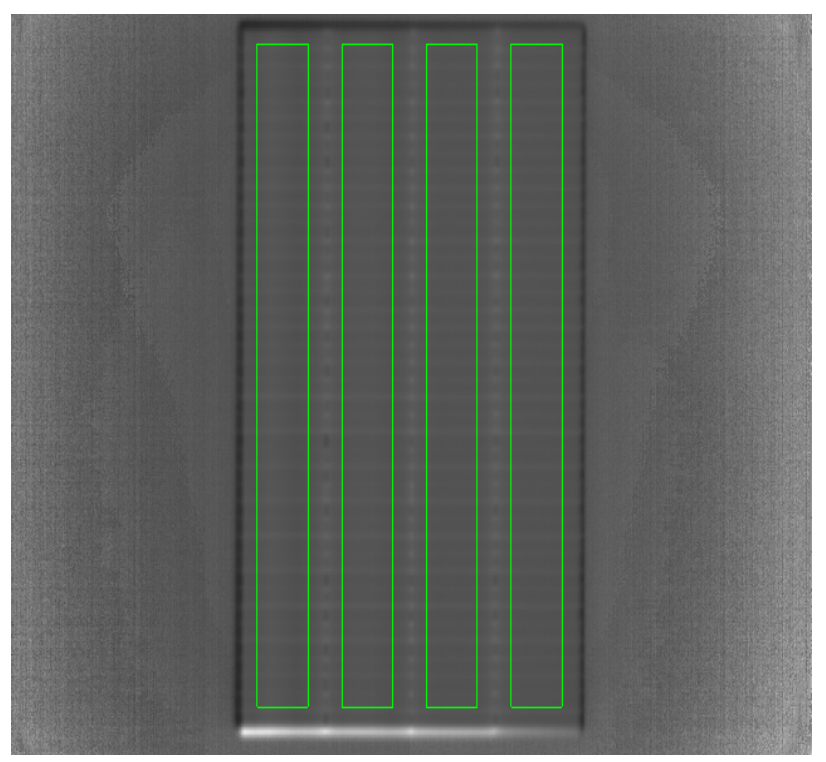

Ryc. 4. Otrzymany obraz dla testu MLC Speed [Źródło: rycina własna].

\section{Wyniki}

W Tabeli I. przedstawiono średnie wartości testów dynamicznych uzyskanych dla wszystkich trzech akceleratorów liniowych. Wartości referencyjne dla każdego parametru zostały wyznaczone na podstawie analizy przeszło 3500 obrazów DICOM, zebranych w czasie 8 miesięcy. Dla testu dMLC dosimetry różnice od wartości średniej nie przekraczały 1,5\% Uzyskane średnie wartości dla testów Static Picket Fence oraz Rapid Picket Fence znajdowały się w przedziale 0,31-o,6omm. Dla aparatu TrueBeam średni błąd pozycjonowania listków dla testu statycznego wynosił $0,31 \mathrm{~mm}$, a dla testu dynamicznego o,41mm. Dla kolimatora wielolistkowego akceleratora Clinac $2300 \mathrm{CD}-\mathrm{S}$, wartości te wynosiły odpowiednio 0,52mm i $0,59 \mathrm{~mm}$, a dla aparatu Unique $0,55 \mathrm{~mm}$ i $0,60 \mathrm{~mm}$. Wyniki testów Dose Rate/Gantry Speed oraz MLC Speed nie przekraczały wartości 2\% dla wszystkich aparatów terapeutycznych.

Tabela I. Wyniki dynamicznych testów MLC uzyskane dla akceleratorów: TrueBeam, Clinac 230o CD-S oraz Unique.

\begin{tabular}{|c|c|c|c|}
\hline Parametr/Akcelerator liniowy & TrueBeam & Clinac 2300 CD-S & Unique \\
\hline dMLC dosimetry & $1,10 \%$ & $0,87 \%$ & $0,93 \%$ \\
\hline Static Picket Fence & $0,31 \mathrm{~mm}$ & $0,52 \mathrm{~mm}$ & $0,55 \mathrm{~mm}$ \\
\hline Rapid Picket Fence & $0,41 \mathrm{~mm}$ & $0,59 \mathrm{~mm}$ & $0,60 \mathrm{~mm}$ \\
\hline Dose Rate/Gantry Speed & $0,82 \%$ & $1,52 \%$ & $1,11 \%$ \\
\hline MLC Speed & $0,89 \%$ & $1,44 \%$ & $1,14 \%$ \\
\hline
\end{tabular}




\section{Dyskusja wyników}

Średnie wartości testu dMLC dosimetry utrzymywały się na podobnym poziomie dla trzech akceleratorów liniowych. Oznacza to, że siła grawitacji ma nieznaczny wpływ na ruch listków kolimatora i dostarczoną dawkę promieniowania jonizującego, podczas zmiennych pozycji obrotu ramienia aparatu. Na podstawie otrzymanych wyników oraz danych literaturowych wyznaczono $2 \%$ zakres tolerancji [12]. Uzyskane wyniki dla statycznych i dynamicznych testów Picket Fence świadczą o tym, że precyzja pozycjonowania listków na aparacie TrueBeam jest większa o około o,20mm niż dla pozostałych akceleratorów. Dla aparatów Clinac 2300 CD-S oraz Unique precyzja pozycjonowania listków mieściła się w przedziale o,52-0,60mm. Wyznaczony na podstawie obserwacji zmienności wyników limit tolerancji wynosi 0,70mm. Dla testu określającego zależność dostarczonej dawki promieniowania od mocy dawki i prędkości obrotu ramienia oraz testu kontrolującego prędkość ruchu listków wyznaczono 2\% tolerancje, bazując na otrzymanych wynikach i danych literaturowych [13].

\section{Wnioski}

Opisane w powyższej pracy testy pozwalają na kontrolę pracy listków, zarówno podczas realizacji techniki IMRT, jak i VMAT. Oprogramowanie do automatycznej analizy obrazów - Artiscan, sprawia, że cały proces kontroli jakości staje się szybszy i bardziej wydajny, umożliwiając analizę bardzo dużej liczby obrazów DICOM w krótkim czasie. Powtarzalność uzyskanych wyników pozwoliła na wyznaczenie zakresów tolerancji i poziomów reagowania, które zautomatyzowały proces kontroli jakości i są stosowane w praktyce klinicznej.

\section{Piśmiennictwo / References}

[1] Krzysztof Ślosarek, Weryfikacja realizacji technik dynamicznych w radioterapii, ISSN 2300-1410/ MNiSW (4), IC (48.69).

[2] Klein EE, Hanley J, Bayouth J, Yin FF, Simon W, Dresser S, Serago C, Aguirre F, Ma L, Arjomandy B, Liu C, Sandin C, Holmes T, Task Group 142 report: quality assurance of medical accelerators. Med Phys. 2009 Sep;36(9):4197-212.

[3] Varian Medical Systems, MLC Systems and Maintenance Guide, P/N 1101018-01, March 1995.

[4] Iori Sumida, Hajime Yamaguchi, Hisao Kizaki, Masahiko Koizumi, Toshiyuki Ogata, Yutaka Takahashi, and Yasuo Yoshioka, Quality assurance of MLC leaf position accuracy and relative dose effect at the MLC abutment region using an electronic portal imaging device. J Radiat Res. 2012 Sep; 53(5): 798-806.

[5] Li Y, Chen L, Zhu J, Wang B, Liu X. A quantitative method to the analysis of MLC leaf position and speed based on EPID and EBT3 film for dynamic IMRT treatment with different types of MLC. J Appl Clin Med Phys. 2017 Jul;18(4):106-115.

[6] Varian Medical Systems, Unique specifications, Varian Medical Systems International AG Cham, Switzerland 03/16.

[7] Varian Medical Systems, TrueBeam specifications, Varian Medical Systems International AG Cham, Switzerland 09/2013.

[8] Varian Medical Systems, Clinac 2300 CD-S specifications, Varian Medical Systems International AG Cham, Switzerland. 01/2014.

[9] Ekambaram Varadharajan, Velayudham Ramasubramanian. Commissioning and Acceptance Testing of the existing linear accelerator upgraded to volumetric modulated arc therapy. Reports of Practical Oncology \& Radiotherapy. Volume 18, Issue 5, September-October 2013, Pages 286-297.

[10] Fang-Fang Yin, PhD, Q. Jackie Wu, PhD. RapidArc: Clinical Implementation. Duke University Medical Center.

[11] Ling CC, Zhang P, Archambault Y, Bocanek J, Tang G, Losasso T. Commissioning and quality assurance of RapidArc radiotherapy delivery system. Int J Radiat Oncol Biol Phys. 2008 Oct 1;72(2):575-81.

[12] E. Calabri, G. Benecchi, R. Rossi, F. Palleri, C. Ghetti. Quality assurance of RapidArc radiotherapy delivery system: RA-commissioning test results. Physica Medica February 2016 Volume 32, Supplement 1. 
[13] Ekambaram VaradharajanVelayudham Ramasubramanian. Commissioning and Acceptance Testing of the existing linear accelerator upgraded to volumetric modulated arc therapy Rep Pract Oncol Radiother. 2013 Sep; 18(5): 286-297.

[14] Artiscan Manual Guide, Parc Eurasanté - Lille Métropole 2016. 